\title{
Effect of Viscoelastic Stress State at Die Exit on Extrusion Film Casting Process: Theoretical Study
}

\author{
Tomas Barborik $^{1, \text { a) }}$ and Martin Zatloukal ${ }^{1, \text { b) }}$ \\ ${ }^{1}$ Polymer Centre, Faculty of Technology, Tomas Bata University in Zlin, \\ nam. T. G. Masaryka 275, 76272 Zlin, Czech Republic \\ a)barborik@ft.utb.cz

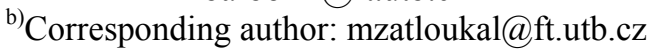

\begin{abstract}
In this work, viscoelastic, isothermal extrusion film casting modeling utilizing 1D membrane model and modified Leonov model was performed in order to understand the role of viscoelastic stress state at the die exit on the polymer melt film stretching in the post die area. Experimental data for LDPE and theoretical predictions based on the eXtended Pom-Pom (XPP) model taken from the open literature were used for the validation purposes. It was found that predicting capabilities of 1D membrane model utilizing XPP and modified Leonov model are comparable for the given processing conditions and material. Consequent theoretical parametric study revealed that increase in the viscoelastic stress state at the die exit, characterized as the ratio of second and first normal stress differences, $-N_{2} / N_{1}$, leads to increase in neck-in phenomenon. This suggests that specific attention should be paid to optimization of the extrusion die design in order to stabilize polymer melt film stretching in the post die area.
\end{abstract}

\section{INTRODUCTION}

Extrusion film casting (EFC) is a continuous manufacturing process during which a thin polymer film is produced. In this process a molten polymer is extruded through a slit die with a narrow gap, then intensively stretched in the machine direction and finally cooled down on a chill roll. During film production, there is number of flow phenomena which may significantly reduce the processing window [1]. Probably the most important ones are neck-in phenomenon (unwanted reduction of the film width) and dog-bone effect (development of very thick edges), which are still not fully understand yet.

EFC has been extensively studied over the past four decades. Many studies focused on the process stability under the steady state. First attempts were conducted on a mathematically similar manufacturing process of the fibre spinning for Newtonian and Maxwell fluids by Gelder [2] and Fisher, Denn [3, 4]. These preliminary approaches prepared the background for the extended studies of EFC, which were based on the assumption of the constant film width neglecting both the neck-in phenomenon and the dog-bone effect [5]. A model considering both, the film width and thickness as the variables, was developed by Sergent [6] and its nonisothermal modification was proposed by Cotto et al. [7], Duffo et al. [8], and Barq et al. [9]. More recently, the membrane model was presented by d'Halewyn et al. [10] and Sakaki et al. [11], and then by Sakaki et al. [12] and Debbaut et al. [13] for Newtonian fluids and viscoelastic fluids, respectively. This frequently used model was capable of predicting the dog-bone effect under the stationary conditions. Silagy et al. [14] continued and enriched membrane model by a supplementary kinematic hypothesis, which was originally brought Narayanaswamy [15] in his paper on float glass stretching, and carried out the extent isothermal study on the process condition and stability of EFC [16, 17]. There has also been done a considerable amount of work on EFC under the non-isothermal conditions by Lamberti et al. [18-20], Lamberti and Titomanlio [21-24], and Titomanlio [25]. Recently, Pol et al. [26, 27] and Chikhalikar et al. [28] have published a series of articles investigating the influence of the polymer molecular structure on the necking development. For this purpose they utilized the 1D membrane model, originally proposed by Silagy et al. [14], the multimode eXtended Pom-Pom constitutive equation and the multimode Rolie-Poly stretch constitutive equation, 
respectively, for the long chain branched (LDPE, PP) and the linear (HDPE, PP) polymers. Even if many useful findings and conclusions regarding to neck-in phenomenon can be found in the open literature [29-33], the effect of polymer melt flow history, generated inside the extrusion die, on the neck-in phenomenon occurring in post die area still remains unclear. In order to extend the knowledge in this field, the 1D membrane model proposed by Silagy et al. [14] together with viscoelastic modified Leonov model [34] was utilized in this work for the EFC modeling.

\section{MODELING}

\section{Modified Leonov Model}

This constitutive equation is based on heuristic thermodynamic arguments resulting from the theory of rubber elasticity [35-37]. Mathematically it is relating the stress and elastic strain stored in the material as:

$$
\underline{\underline{\tau}}=2\left(\underline{\underline{c}} \frac{\partial W}{\partial I_{1}}-\underline{\underline{c}}^{-1} \frac{\partial W}{\partial I_{2}}\right)
$$

where $\underline{\underline{\tau}}$ is the stress, and $W$, the elastic potential, which depends on the invariants $I_{1}$ and $I_{2}$ of the recoverable Finger tensor $\underline{\underline{c}}$,

$$
W=\frac{3 G}{2\left(n_{0}+1\right)}\left\{(1-\beta)\left[\left(\frac{I_{1}}{3}\right)^{n_{0}+1}-1\right]+\beta\left[\left(\frac{I_{2}}{3}\right)^{n_{0}+1}-1\right]\right\}
$$

where $G$ denotes linear Hookean elastic modulus, $\beta$ and $n_{0}$ are numerical parameters. Leonov assumed that dissipative process act to produce irreversible rate of strain $e_{\mathrm{p}}$

$$
\underline{\underline{e}}_{p}=b\left[\underline{\underline{c}}-\left(\frac{I_{1}}{3}\right) \underline{\underline{\delta}}\right]-b\left[\underline{\underline{c}}^{-1}-\left(\frac{I_{2}}{3}\right) \underline{\underline{\delta}}\right]
$$

which spontaneously reduces the rate of elastic strain accumulation. Here, $\underset{=}{\delta}$ is the unit tensor and $b$ stands for dissipation function defined by Eq. 5.This elastic strain $\underline{\underline{c}}$ is related to the deformation rate tensor $\underline{\underline{D}}$ as follows

$$
\stackrel{0}{\underline{\underline{c}}}-\underline{\underline{c}} \cdot \underline{\underline{D}}-\underline{\underline{D}} \cdot \underline{\underline{c}}+\underline{\underline{c}} \cdot \underline{\underline{e}} \underline{p}=0
$$

where $\stackrel{0}{\underline{\underline{c}}}$ is the Jaumann (corotational) time derivative of the recoverable Finger strain tensor. In this work, the neoHookean potential (i.e. $\beta=n_{0}=0$ in Eq. 2) and the dissipation function $b$ proposed in [34] (see Eq. 5), have been employed.

$$
b\left(I_{1}\right)=\frac{1}{4 \lambda}\left\{\exp \left(-\xi \sqrt{I_{1}-3}\right)+\frac{\sinh \left[v\left(I_{1}-3\right)\right]}{v\left(I_{1}-3\right)+1}\right\}
$$

Here, $\xi$ and $v$ are adjustable parameters which are allowed to wary with relaxation time, $\lambda$.

$$
\begin{gathered}
I_{1}=\operatorname{tr}(\underline{\underline{c}})=c_{x x}+c_{y y}+c_{z z} \\
\left.I_{2}=\{\operatorname{tr}(\underline{\underline{c}})]^{2}-\operatorname{tr}\left(\underline{\underline{c^{2}}}\right)\right\}=c_{x x}^{-1}+c_{y y}^{-1}+c_{z z}^{-1}
\end{gathered}
$$




\section{Extrusion Film Casting Model}

In this work, the one-dimensional membrane model developed by Silagy et al. [14] was used to model film casting process (see Fig. 1).

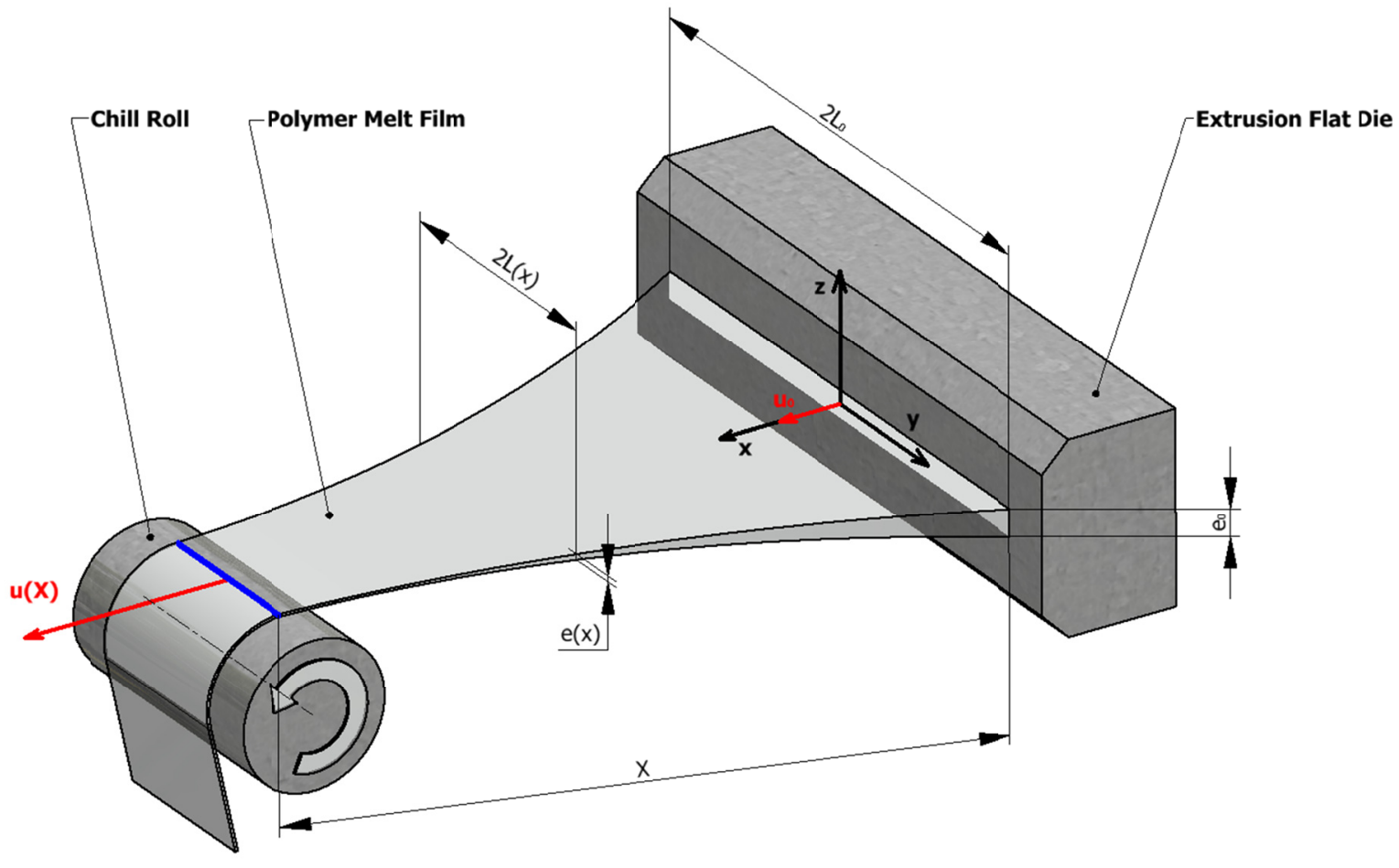

FIGURE 1. Schematic of the extrusion film casting process (kinematic).

The model assumes that the thickness of the film is small in comparison to the other film dimensions, and the machine direction velocity component $u$ is dependent only on the $x$ variable. The velocity field is then given by the following set of equations:

$$
\begin{aligned}
& u=u(x) \\
& v=v(x, y)=y f(x) \\
& w=w(x, z)=z g(x)
\end{aligned}
$$

where $u(\mathrm{x}), u(\mathrm{x}, \mathrm{y})$, and $w(\mathrm{x}, \mathrm{z})$ are the velocity components in the machine, transverse, and thickness direction, respectively. The rate of deformation tensor based on Eq. 8 is:

$$
\dot{\varepsilon}=\left[\begin{array}{ccc}
\frac{d u}{d x} & \frac{1}{2} y \frac{d f}{d x} & \frac{1}{2} z \frac{d g}{d x} \\
\frac{1}{2} y \frac{d f}{d x} & f(x) & 0 \\
\frac{1}{2} z \frac{d g}{d x} & 0 & g(x)
\end{array}\right]
$$


Since the polymer flow in the EFC is mainly extensional and in an effort to increase simplicity, it enables us to neglect the shear rate components in the matrix Eq. 9, then we obtain:

$$
D=\left[\begin{array}{ccc}
\frac{d u}{d x} & 0 & 0 \\
0 & \frac{u}{L} \frac{d L}{d x} & 0 \\
0 & 0 & \frac{u}{e} \frac{d e}{d x}
\end{array}\right]
$$

The modified Leonov model constitutive equation was integrated into the essential equations of the membrane model: the continuity equation and the momentum conservation equation. The final set of dimensionless equations after a rearrangement has a form of the recoverable strain derivatives $d c_{\mathrm{ii}} / d i$ in the particular directions Eqs. 11, 12 and 13.

$$
\begin{gathered}
\frac{d c_{x x}}{d \bar{x}}=2 c_{x x} \frac{1}{\bar{u}} \frac{d \bar{u}}{d \bar{x}}-\frac{2 b}{\bar{u}} Z_{x} \\
\frac{d c_{y y}}{d \bar{x}}=2 c_{y y} \frac{1}{\bar{L}} \frac{d \bar{L}}{d \bar{x}}-\frac{2 b}{\bar{u}} Z_{y} \\
\frac{d c_{z z}}{d \bar{x}}=2 c_{z z} \frac{1}{\bar{e}} \frac{d \bar{e}}{d \bar{x}}-\frac{2 b}{\bar{u}} Z_{z} \\
z_{i}=c_{i i}\left(c_{i i}-c_{i i}^{-1}+X_{p}\right) \\
X_{p}=\frac{1}{3}\left(c_{x x}^{-1}+c_{y y}^{-1}+c_{z z}^{-1}-c_{x x}-c_{y y}-c_{z z}\right)
\end{gathered}
$$

And finally the derivative of the axial velocity with respect to $\mathrm{x}$ is defined as:

$$
\begin{gathered}
\frac{d \bar{u}}{d \bar{x}}=\frac{d \bar{\tau}_{x x}}{d \bar{x}}-\frac{d \bar{\tau}_{z z}}{d \bar{x}} \rightarrow \frac{d \bar{u}}{d \bar{x}}=\frac{E}{D e}\left(\frac{d c_{x x}}{d \bar{x}}-\frac{d c_{z z}}{d \bar{x}}\right) \\
\operatorname{IF}\left(n_{0}=\beta=0\right) \quad \frac{d \bar{u}}{d \bar{x}}=\frac{b\left(Z_{z}-Z_{x}\right)+\frac{\bar{u}}{\bar{L}} \frac{d \bar{L}}{d \bar{x}} c_{z z}}{\frac{D e \bar{u}}{2 E}-c_{x x}-c_{z z}}
\end{gathered}
$$

The relationship between the stress and the recoverable strain, implied from the modified Leonov model, can be described by the following formula:

$$
\bar{\tau}=\bar{G} c
$$

As the boundary conditions for an individual solution, it was assumed that the edge of the film is a free surface, i.e. mathematically it leads to Eqs. 19, 20 and 21.

$$
\bar{\tau}_{x x}-\bar{\tau}_{z z}=\bar{u} \rightarrow \bar{\tau}_{x x}-\bar{\tau}_{z z}=1 \quad \text { at } \quad \bar{x}=0
$$




$$
\begin{gathered}
c_{x x} c_{y y} c_{z z}=1 \\
\frac{E}{D e}\left(c_{x x}+c_{z z}\right)=1
\end{gathered}
$$

The whole system of the first-order ordinary differential equations was then numerically solved by the fourth order Runge-Kutta method incorporating the shooting method. The input parameters were updated in each iteration step to meet the appropriate solution. It was preferred to develop the solver itself in the $\mathrm{C}++$ programming language, to avoid a black box effect, which could have appeared in the case of using a inbuilt solver in any other commercial mathematical-modeling software. The equation evaluation was performed on the PC with the following hardware parameters: CPU Intel Core 2 Quad Q9650 (3.00 GHz), RAM 8 GB DDR2, GPU Sapphire Radeon HD 3870, HDD WD 300 GB 10k rpm. Typical computational time for one calculation was 2 minutes.

The equation of continuity

$$
\frac{d}{d x}(e L u)=0
$$

The equation of motion

$$
\begin{gathered}
\frac{d}{x}\left(\sigma_{x x} L e\right)=\frac{d F}{d x}=0 \\
F=\text { const }=\sigma_{x x} L e
\end{gathered}
$$

Membrane approximation

$$
\begin{gathered}
\sigma_{z z}=\frac{0}{E} \\
\tau_{z z}=p \\
\sigma_{x x}=\tau_{x x}-\tau_{z z} \\
\left(\tau_{x x}-\tau_{z z}\right) L e=F
\end{gathered}
$$

The stress free surface condition

$$
\begin{gathered}
\left(\frac{d L}{d x}\right)^{2}=\frac{\sigma_{y y}}{\sigma_{x x}} \\
L_{0}-L=\int_{0}^{X} \sqrt{\frac{\sigma_{y y}}{\sigma_{x x}}} d x=\int_{0}^{X} \sqrt{\frac{\tau_{y y}-\tau_{z z}}{\tau_{x x}-\tau_{z z}}} d x \approx X \sqrt{\frac{\tau_{y y}-\tau_{z z}}{\tau_{x x}-\tau_{z z}}} \\
\frac{d \bar{L}}{d \bar{x}}=-A \sqrt{\frac{\bar{\tau}_{y y}-\bar{\tau}_{z z}}{\bar{\tau}_{x x}-\bar{\tau}_{z z}}}
\end{gathered}
$$


The continuity equation and the momentum equation

$$
\begin{gathered}
\bar{e} \bar{L} \bar{u}=1 \\
\left(\bar{\tau}_{x x}-\bar{\tau}_{z z}\right)=\bar{u}
\end{gathered}
$$

Differentiating the continuity equation and the momentum equation with respect to x, we obtain Eq. 34 and 35 .

$$
\begin{gathered}
\frac{1}{=} \frac{d \bar{e}}{d \bar{x}}+\frac{1}{\bar{L}} \frac{d \bar{L}}{d \bar{x}}+\frac{1}{=} \frac{d \bar{u}}{d \bar{x}}=0 \rightarrow \frac{d \bar{e}}{d \bar{x}}=-\left(\frac{1}{\bar{L}} \frac{d \bar{L}}{d \bar{x}}+\frac{1}{\bar{u}} \frac{d \bar{u}}{d \bar{x}}\right) \bar{e} \\
\frac{\bar{\tau}_{x x}}{d \bar{x}}-\frac{\bar{\tau}_{z z}}{d \bar{x}}-\frac{d \bar{u}}{d \bar{x}}=0
\end{gathered}
$$

All applied dimensionless conversions are provided bellow.

$$
\begin{gathered}
\bar{\tau}_{i i}=\frac{\tau_{i i} e_{0} L_{0}}{F} \\
\bar{x}=\frac{x}{X} \\
\bar{e}=\frac{e}{e_{0}} \\
\bar{L}=\frac{L}{L_{0}} \\
\bar{u}=\frac{u}{u_{0}}, D R=\frac{u(X)}{u_{0}} \\
\bar{f}=\frac{L_{0}}{u_{0}} f \\
\bar{g}=\frac{e_{0}}{u_{0}} g \\
\frac{1}{E}=\frac{F X}{G \lambda e_{0} L_{0} u_{0}} \\
D e=\frac{\lambda u_{0}}{X} \\
L_{0} \\
\bar{X}
\end{gathered}
$$




\section{Film Casting Model Validation}

In order to validate the utilized film casting model, we have used the recent experimental and theoretical data provided in [27] for the LDPE 170A polymer. It is important to mention that even if the LDPE 170A is characterized by the relaxation spectrum provided in Tab. 1, the single-mode modified Leonov model was utilized in this work to simplify the calculation.

TABLE 1. Relaxation spectrum for LDPE $170 \mathrm{~A}$ at $150^{\circ} \mathrm{C}$, flow activation energy $40 \mathrm{~kJ} \cdot \mathrm{mol}^{-1}$.

\begin{tabular}{ccc}
\hline \multicolumn{3}{c}{ Maxwell parameters } \\
$\mathbf{i}$ & $\boldsymbol{\lambda}_{\mathbf{i}}(\mathbf{s})$ & $\boldsymbol{G}_{\mathbf{i}}(\mathbf{P a})$ \\
\hline 1 & 0.01 & 93906.53 \\
2 & 0.045 & 31338.38 \\
3 & 0.2 & 23002.11 \\
4 & 0.91 & 11435.39 \\
5 & 4.11 & 5505.88 \\
6 & 12.53 & 1845.06 \\
7 & 61.44 & 527.83 \\
8 & 305.79 & 129.04 \\
\hline
\end{tabular}

For such purpose, the average relaxation time $\langle\lambda\rangle$ and the average modulus $\langle G\rangle$ were calculated from the full relaxation spectrum according to the following formulas taken from [38]:

$$
\begin{aligned}
& \langle\lambda\rangle=\sum_{i=1}^{N} \frac{G_{i} \lambda_{i}^{2}}{G_{i} \lambda_{i}} \\
& \langle G\rangle=\frac{\sum_{i=1}^{N} G_{i} \lambda_{i}}{\sum_{i=1}^{N} \frac{G_{i} \lambda_{i}^{2}}{G_{i} \lambda_{i}}}
\end{aligned}
$$

Remaining non-linear parameters of the modified Leonov model were identified by using deformation rate dependent 'steady state' uniaxial extensional viscosity experimental data taken from Fig. 2b in [27] (i.e. from the peaks appearing on the transient extensional viscosity curves for corresponding extensional strain rates). Obtained model parameters are provided in Tab. 2. Interestingly, the measured data can be represented by the single-mode modified Leonov model very well as shown in Fig. 2a.

TABLE 2. Modified Leonov model parameters for $T=190^{\circ} \mathrm{C}$; LDPE 170A.

Maxwell parameters mLeonov model

\begin{tabular}{ccccc}
$\mathbf{i}$ & $\boldsymbol{\lambda}_{\mathbf{i}}(\mathbf{s})$ & $\boldsymbol{G}_{\mathbf{i}}(\mathbf{P a})$ & $\boldsymbol{\xi}$ & $\boldsymbol{\nu}$ \\
\hline 1 & 144.2249 & 350.5985 & 0.35 & 0.00055 \\
\hline
\end{tabular}



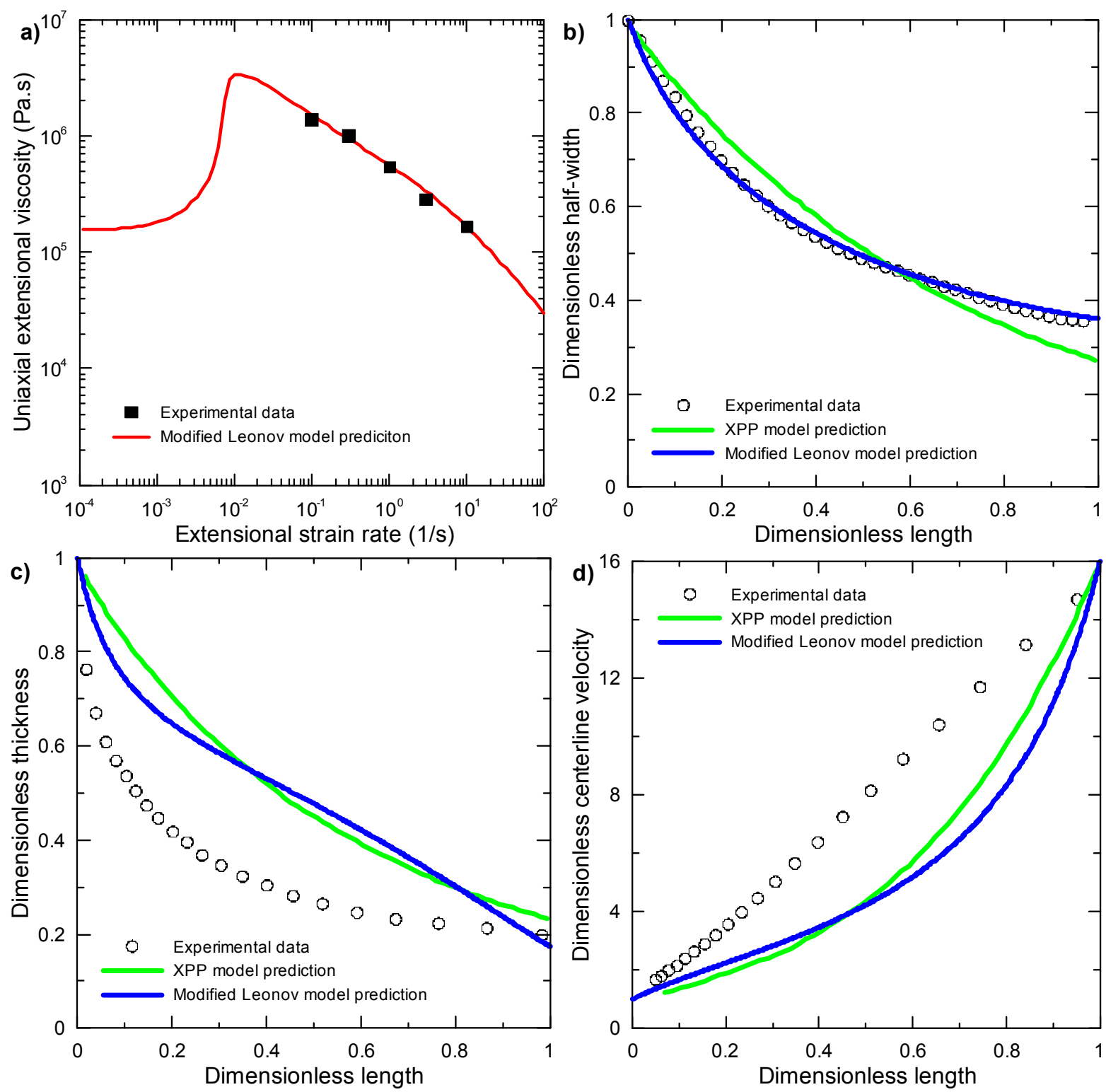

FIGURE 2. Comparison between experimental data for LDPE $170 \mathrm{~A}$ and given processing conditions $(\mathrm{DR}=16$ and $\mathrm{X}=230 \mathrm{~mm})$ taken from the open literature [27] and corresponding model predictions. 2a) LDPE 170A extensional rheology, 2b) Film width profile between die and roll, 2c) Film thickness profile between die and roll, 2d) Velocity profile between die and roll.

Modeled processing conditions for the film casting process were the same as described in [27], i.e. isothermal, die width $=100 \mathrm{~mm}$, gap size $=0.46 \mathrm{~mm}$, melt exit velocity $=4.3 \mathrm{~mm} \cdot \mathrm{s}^{-1}$, and distance between the die and roll $230 \mathrm{~mm}$.

In the fully viscoelastic calculation based on the modified Leonov model, it is necessary to define the stress state at the end of the extrusion die, namely the ratio of the second normal stress difference, $N_{2}$, and first normal stress difference, $N_{1}$, which are generated by the shear flow. However, this rheological characteristic is not available for the given LDPE 170A from [27] and thus experimentally determined $-N_{2} / N_{1}=0.39$ value taken from [39] for another type of LDPE was used here to define the boundary condition at the die exit. Comparison between the film casting model predictions based on the single-mode modified Leonov model (this work), multi-mode XPP model and the corresponding experimental data (both taken from [27]) is provided in Fig. 2b-2d. As can be seen, behavior of both models is comparable and the agreement with the experimental data is the highest for the film width profile and the final film thickness. Such a reasonably good agreement with the experimental data justifies to use even single-mode Leonov model for detailed parametric study. 


\section{Theoretical Parametric Study}

In this part, the effect of flow history generated inside the extrusion die on the film casting process is investigated theoretically. It is well known that due to the viscoelastic nature of polymer melts, they have fading memory, and thus, the final stress state of the polymer melt at the die exit (represented here by $-N_{2} / N_{1}$ ratio) depends also on the flow channel characteristics such as gap size and die land length. In order to understand the role of die exit stress state on the film stretching in post die area, the calculations performed in the previous chapter were repeated for the same processing conditions and polymer type but different $-N_{2} / N_{1}$ ratios at the die exit. Results are provided in Figs. 3a-d for film width, thickness and velocity profiles as well as for the final film width. As it can be seen, the predicted effect of $-N_{2} / N_{1}$ ratio on the film casting process is considerable. The most importantly, if the $N_{2} / N_{1}$ ratio increases the neck-in increases too as shown in Fig. 3a. This suggests that specific attention must be paid during die design development and extrusion processing conditions adjustment for given polymer in order to control the viscoelastic stress state at the die exit for neck-in phenomenon minimization.
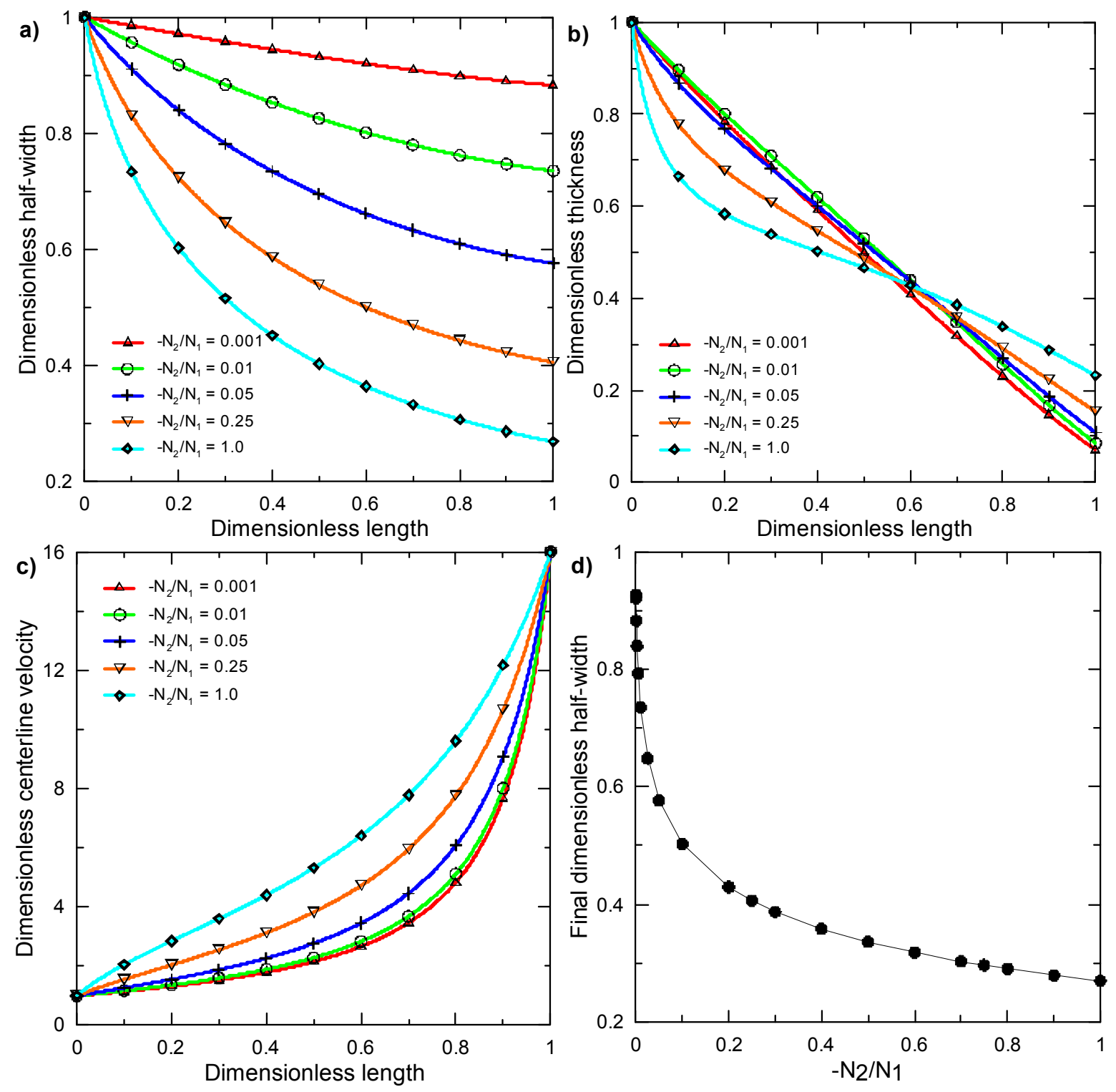

FIGURE 3. The effect of $-N_{2} / N_{1}$ ratio at the die exit on the film width, thickness and velocity during the film casting process for LDPE 170A and given processing conditions $(D R=16$ and $X=230 \mathrm{~mm})$. 3a) Width profile between die and roll, 3b) Thickness profile between die and roll, 3c) Velocity profile between die and roll, 3d) Final dimensionless half-width of the film. 


\section{CONCLUSION}

In this work, viscoelastic, isothermal extrusion film casting modeling utilizing 1D membrane model and single mode modified Leonov model was performed in order to understand the role of viscoelastic stress state at the die exit on the polymer melt film stretching in the post die area. The experimental data for the LDPE 170A as well as corresponding predictions based on the multi-mode XPP model taken from the open literature were utilized for the validation purposes. It was found that the film casting modeling by using multi-mode XPP model and modified Leonov model is comparable for the given polymer and processing conditions even if, surprisingly, single-mode version of the Leonov model, based on the average relaxation time and the average modulus only, was used. The consequent parametric study revealed that viscoelastic stress state at the die exit, expressed here as the $-N_{2} / N_{1}$ ratio, can significantly influence the polymer melt film stretching in the post die area namely, the film width, thickness and velocity profiles. It was found that increase in $-N_{2} / N_{1}$ ratio at the die exit leads to increase in the neck-in phenomenon, which suggests that the specific attention should be paid to optimization of the extrusion die design in order to stabilize polymer melt film stretching in the post die area.

\section{ACKNOWLEDGMENTS}

This study was supported by the internal grant of TBU in Zlín IGA/FT/2015/013 funded from the resources of specific university research.

\section{LIST OF SYMBOLS}

$\begin{array}{lll}\underset{\underline{\tau}}{\underline{W}} & \text { Stress tensor } & \mathrm{Pa} \\ G & \text { Elastic potential } & \mathrm{Pa} \\ I_{1, \mathrm{c}} & \text { Linear Hookean elastic modulus (Relaxation modulus) } & \mathrm{Pa} \\ I_{2, \mathrm{c}} & \text { First invariant of recoverable Finger tensor } & 1 \\ \underline{c}, c_{i i} & \text { Second invariant of recoverable Finger tensor } & 1 \\ \underline{c}^{-1}, c_{i i}^{-1} & \text { Recoverable Finger tensor } & 1 \\ \beta & \text { Inverse recoverable Finger tensor } & 1 \\ n_{0} & \text { Non-linear Leonov model parameter } & 1 \\ \underline{e} & \text { Non-linear Leonov model parameter } & 1 \\ b & \text { Irreversible rate of strain tensor } & \mathrm{s}^{-1} \\ \delta & \text { Dissipation term } & 1 \\ \underline{D} & \text { Unit tensor (Kronecker delta) } & 1 \\ \underline{D} & \text { Deformation rate tensor } & \mathrm{s}^{-1} \\ \lambda & \text { Relaxation time } & \mathrm{s} \\ \xi & \text { Non-linear Leonov model parameter } & 1 \\ v & \text { Non-linear Leonov model parameter } & 1 \\ 0 & \text { Jaumann (corotational) time derivative of the recoverable Finger strain tensor } & \mathrm{s}^{-1} \\ \underline{\underline{c}} & \text { First normal stress difference } & \mathrm{Pa} \\ N_{1} & \text { Second normal stress difference } & \mathrm{Pa} \\ N_{2} & \text { Total normal stress in the axial direction (machine direction) } & \mathrm{Pa} \\ \sigma_{x x} & \text { Total normal stress in y-direction } & \mathrm{Pa} \\ \sigma_{y y} & \text { Total normal stress in z-direction } & \mathrm{Pa} \\ \sigma_{z z} & \text { Normal stress in the axial direction (machine direction) } & \mathrm{Pa} \\ \tau_{x x} & \text { Normal stress in y-direction } & \mathrm{Pa} \\ \tau_{y y} & \text { Normal stress in z-direction } & \mathrm{Pa} \\ \tau_{z z} & \text { Isotropic pressure } & \mathrm{Pa} \\ p & \text { Component of the recoverable Finger tensor in x-direction } & 1\end{array}$




\begin{tabular}{|c|c|}
\hline$c_{y y}$ & Component of the recoverable Finger tensor in y-direction \\
\hline$c_{z z}$ & Component of the recoverable Finger tensor z-direction \\
\hline$e^{2}$ & Thickness of the film at any $x$ location \\
\hline$L$ & Half-width of the film at any $x$ location \\
\hline$u$ & Axial velocity of the film at any $\mathrm{x}$ location \\
\hline$u(X)$ & Chill roll speed \\
\hline$F$ & Take-up force (stretching force) \\
\hline$x$ & Position in $\mathrm{x}$-direction \\
\hline$v$ & Velocity of the film in $\mathrm{y}$-direction at any $\mathrm{x}$ location \\
\hline$w$ & Velocity of the film in $\mathrm{z}$-direction at any $\mathrm{x}$ location \\
\hline$f$ & Rate of deformation in y-direction \\
\hline$g$ & Rate of deformation in z-direction \\
\hline$e_{0}$ & Die gap (Thickness of the film at the die exit) \\
\hline$L_{0}$ & $\begin{array}{l}\text { Half-width of the die at the initial position (Half-width of the film at the die } \\
\text { exit) }\end{array}$ \\
\hline$u_{0}$ & Axial velocity at the die exit (velocity in the machine direction) \\
\hline$X$ & Take-up length (stretching distance) \\
\hline$D R$ & Draw ratio \\
\hline$A$ & Aspect ratio \\
\hline De & Deborah number \\
\hline E & Dimensionless force \\
\hline $\bar{x}$ & Dimensionless position in $\mathrm{x}$-direction \\
\hline $\bar{e}$ & Dimensionless thickness of the film at any $\mathrm{x}$ location \\
\hline $\bar{L}$ & Dimensionless half-width of the film at any $\mathrm{x}$ location \\
\hline $\bar{u}$ & Dimensionless axial velocity of the film at any $\mathrm{x}$ location \\
\hline $\bar{\tau}_{x x}$ & Dimensionless normal stress in $\mathrm{x}$-direction \\
\hline $\bar{\tau}_{y y}$ & Dimensionless normal stress in y-direction \\
\hline $\bar{\tau}_{z z}$ & Dimensionless normal stress in z-direction \\
\hline $\bar{G}$ & Dimensionless linear Hookean elastic modulus \\
\hline $\bar{f}$ & Dimensionless rate of deformation in y-direction \\
\hline$g$ & Dimensionless rate of deformation in z-direction \\
\hline$Z_{x}, Z_{y}, Z_{y}, X_{p}$ & Substitution variables \\
\hline
\end{tabular}

\section{REFERENCES}

1. T. Kanai and G. A. Campbell, Film Processing Advances (Carl Hanser Verlag GmbH \& Co. KG., München, 2014), pp. 133-193.

2. D. Gelder, Corresp. IM. Eng. Chern. Fund. 10(3), 534-535 (1971).

3. R. J. Fisher and M. M. Denn, Chem. Eng. Sci. 30, 1129-1134 (1975).

4. R. J. Fisher and M. M. Denn, AlChE J. 22(2), 236-246 (1976).

5. Y. L. Yeow, J. Fluid Mech. 68, part 3, 613-622 (1974).

6. J-P. Sergent, These de Doctorat, Universite Louis Pasteur, Strasbourg (1977).

7. D. Cotto, P. Duffo, and J-M. Haudin, Int. Polym. Process. IV(2), 103-113 (1989).

8. P. Duffo, B. Monasse, and J-M. Haudin, J. Polym. Eng. 10(1-3), 151-229 (1991).

9. P. Barq, J-M. Haudin, and J-F. Agassant, Int. Polym. Process. VII(4), 334-349 (1992).

10. S. d'Halewyn, J-F. Agassant, and Y. Demay, Polym. Eng. Sci. 30(6), 335-340 (1990).

11. K. Sakaki, T. Kajiwara, and K. Funatsu, Proceedings of the 10th Annual Meeting of the Polymer Processing Society (PPS), 321 (1994). 
12. K. Sakaki, T. Kajiwara, and K. Funatsu, Proceedings of the 11th Annual Meeting of the Polymer Processing Society (PPS), 183 (1995).

13. B. Debbaut, J. M. Marchal, and M. J. Crochet, Zangew. Math. Phys. 46, 679-698 (1995).

14. D. Silagy, Y. Demay and J. F. Agassant, Polym. Eng. Sci. 36(21), 2614-2625 (1996).

15. O. S. Narayanaswamy, J. Americ. Ceramic Soc., 60(1-2), 1-5 (1977).

16. D. Silagy, Y. Demay and J. F. Agassant, J. Non-Newtonian Fluid Mech. 79(2-3), 563-583 (1998).

17. D. Silagy, Y. Demay and J. F. Agassant, Int. J. Numeric. Methods in Fluids, 30(1), 1-18 (1999).

18. G. Lamberti, G. Titomanlio and V. Brucato, Chem. Eng. Sci. 56(20), 5749-5761 (2001).

19. G. Lamberti, G. Titomanlio and V. Brucato, Chem. Eng. Sci. 57(11), 1993-1996 (2002).

20. G. Lamberti, V. Brucato, and G. Titomanlio, J. App. Polym. Sci. 84(11), 1981-1992 (2002).

21. G. Lamberti, and G. Titomanlio, Macromol. Symposia, 185(1), 167-180 (2002).

22. G. Titomanlio and G. Lamberti, Rheol. Acta, 43(2), 146-158 (2004).

23. G. Lamberti and G. Titomanlio, Chem. Eng. Process.: Process Intensification, 44(10), 1117-1122 (2005).

24. G. Lamberti, and G. Titomanlio, Indust. \& Eng. Chem. Research, 45(2), 719-723 (2006).

25. G. Lamberti, Polym. Eng. Sci. 51(5), 851-861 (2011).

26. H. V. Pol, S. S. Thete, P. Doshi and A. K. Lele, J. Rheol. 57(2), 559-583 (2013).

27. H. Pol, S. Banik, L. B. Azad, S. Thete, P. Doshi and A. Lele, Rheol. Acta 53(1), 85-101 (2014).

28. K. Chikhalikar, S. Banik, L. B. Azad, K. Jadhav, S. Mahajan, Z. Ahmada and A. Lele, Polym. Eng. Sci. (2014). Article in Press (DOI: 10.1002/pen.24039).

29. T. Dobroth and L. Erwin, Polym. Eng. Sci. 26(7), 462-467 (1986).

30. N. Satoh, H. Tomiyama and T. Kajiwara, Polym. Eng. Sci. 41(9), 1564-1579 (2001).

31. T. Kajiwara, M. Yamamura and T. Asahina, Nihon Reoroji Gakkaishi 34(2), 97-103 (2006).

32. S. Shiromoto, Y. Masutani, M. Tsutsubuchi, Y. Togawa and T. Kajiwara, Polym. Eng. Sci. 50(1), 22-31 (2010).

33. S. Shiromoto, Y. Masutani, M. Tsutsubuchi, Y. Togawa and T. Kajiwara, Rheol. Acta 49, 757-767 (2010).

34. M. Zatloukal, J. Non-Newtonian Fluid Mech. 113(2-3), 209-227 (2003).

35. A. I. Leonov, Rheol. Acta, 15(2), 85-98 (1976).

36. M. Simhambhatla and A. I. Leonov, Rheol. Acta, 34(3), 259-273 (1995).

37. A. I. Leonov, Rheol. Series 8, 519-575 (1999).

38. E. Mitsoulis, I. B. Kazatchkov and S. G. Hatzikiriakos, Rheol. Acta 44(4), 418-426 (2005).

39. E. A. Jensen and J. deC. Christiansen, J. Non-Newtonian Fluid Mech. 148(1-3), 41-46 (2008). 
AIP Conference Proceedings is copyrighted by AIP Publishing LLC (AIP). Reuse of AIP content is subject to the terms at: http://scitation.aip.org/termsconditions. For more information, see http://publishing.aip.org/authors/rights-and-permissions. 